\title{
Effect of Rainfall on Traffic Stream Characteristics during Peak and Non-Peak Periods
}

\author{
Hashim Mohammed Alhassan ${ }^{* 1}$, Johnnie Ben-Edigbe \\ ${ }^{*}$ Faculty of Civil Engineering, Universiti Teknologi Malaysia, Skudai, 81310, Malaysia \\ ${ }^{1}$ Bayero University Kano, Gwarzo Road, 700241, Nigeria \\ E-mail: mahashim2@live.utm.my \\ ${ }^{\#}$ Faculty of Civil Engineering, Universiti Teknologi Malaysia, Skudai, 81310, Malaysia \\ E-mail: edigbea@yahoo.com
}

\begin{abstract}
This paper examined the effect of rainfall on traffic stream behaviour during peak and non-peak periods on a basic highway section. Data on this section which is located on the J5 was collected for four months during which 99 rainfall events occurred. The traffic consisted of $75.80 \%$ cars, $10.23 \%$ motorcycles, $3.51 \%$ trucks and $10.46 \%$ of other vehicles. Traffic was observed for both rain and no-rain conditions and the data was analysed to see the effect of the rain. The results showed decreases in the speed as the rain intensity increased. Similarly, the traffic flow rates decreased as the rain intensity increased. This trend was observed for both peak and non-peak periods and for both directions. It is concluded that the effect of rain during peak period could have more serious consequences on the traffic flow than during non-peak periods because of the higher flow rates and the constrained nature of the flow. Consequently, capacity degradations up to $30 \%$ during peak periods would require resources to be employed to manage the traffic.
\end{abstract}

Keywords - Traffic Stream; Peak Period; Non-Peak Period; Rainfall Intensity; Highway Capacity; Speed-Density; Flow-Density.

\section{INTRODUCTION}

The macroscopic traffic flow parameters of speed, volume and density are continually being employed in the qualitative and quantitative assessment of Freeways and Urban road networks. These parameters are now regularly monitored on freeway systems where loop detectors have been installed with a view to ensuring the sustainability and efficiency of traffic flows. The increasing urbanisation, vehicle population growth and congestions within the urban conurbations, in addition to limited urban space to add more lanes to existing infrastructure have made technical improvement in traffic management more attractive. Traffic demand from the various urban land uses eventually converge on the major arterial highways and freeways. During certain times of the day, the demand reaches its maximum value and traffic flow instabilities develop. At certain points on the network, the demand overwhelms the traffic carrying ability of the road. The unfolding scenario at these locations includes queue build up, excessive travel times over short distances, fuel consumption and economic loss. These conditions are also common at bottleneck locations such as on-off ramps, intersections, points of geometric lane changes etc.

It is known that rainfall exacerbates these conditions, inducing speed drops and causing further flow contractions, thus making mobility, and comfort of motorists difficult and safety, a major concern. Alhassan and Ben-Edigbe [1,2] , Aggarwal et al.,[3] and Billot et al. [4] among others have indicated that traffic flow parameters are degraded by rainfall. Earlier evidence about the effect of rainfall on traffic flow parameters have been given by Tanner [5] who observed reduction in traffic volume between two weeks in August of 1949 and 1950 and compared the weekend flows between these periods. There were $1.3 \%$ and $3.1 \%$ differences between the weekday and weekend traffic flows. Other studies [6-9], have similarly pointed to various contractions of flow during rainfall including reductions in speed and increases in small headways.

The problems of highway capacity reductions as a result of rainfall have been reported also by [10] who found traffic demand reductions by $2.9 \%$ during weekdays and by $7.9 \%$ on Saturday and 5.2\% on Sunday. Chung et al. [11] have reported capacity reduction in light rain to be $4.7 \%$ and $14 \%$ in heavy rain while Alhassan and Ben-Edigbe $[12,13]$ have 
confirmed reductions in capacity with increasing rainfall intensity variability. Alhassan and Ben-Edigbe [12, 13] further give the state of the traffic under rainfall conditions. These are required for decision support on improvements to be made on these facilities as well as management of traffic in adverse weather.

This presupposes that, the problem of congestion, queue build-up and other undesirable consequences of peak period flows in normal weather conditions could be aggravated in inclement weather. It will seem reasonable to investigate how rainfall combines with the instabilities associated with peak period flows to further degrade qualitative and quantitative indices of traffic flow. This will assist greatly in evolving strategies towards traffic management in inclement weather.

This paper is an empirical study into the effects of rainfall on traffic flows particularly during peak periods or rush hours. The major task is to compare traffic states during peak hours and non-peak hours during rainfall as well as with traffic in normal weather. The rest of the paper is organised as follows: The data collection follows in section II and the results are presented in section III. The conclusions are then stated in section IV

\section{DATA}

A two-way single carriageway facility called the J5 in Johor Bahru State of Malaysia was identified as suitable for this study. A basic section of J5 that was well marked with excellent pavement condition was used to collect data for four months. An automatic traffic counter (MC5600) was installed which recorded detailed vehicle information that passed by the observation point and a nearby rain gauge station provided 5minute rainfall resolution data. This was used to correlate the rainfall times with the traffic data and to abstract the relevant data subsets for analysis. The coupled rainfall and traffic data were used to further classify the traffic as light rain condition, medium rain condition and heavy rain condition. Furthermore, these traffic conditions which coincided with peak and non-peak periods were again separated and analysed. In all 99 rainfall events were observed during the four month period and the peak periods for the Skudai-Pontian direction was from 5-6pm and 6-7pm, while the peak period in the Pontian-Skudai direction was 78am. A total of 1,316,834 vehicles were observed during the period of which $75.80 \%$ were cars and $10.23 \%$ were motorcycles. The truck composition was $3.51 \%$ and the remaining vehicles in the traffic stream were $10.46 \%$. In view of the unique nature of motorcycle behaviour, their effect was filtered out of the traffic data. The highway facility has a posted speed limit of $60 \mathrm{~km} / \mathrm{hr}$. Also the ambient temperature, wind speeds and humidity at the observation site were considered safe for vehicle operation. Thus only the effect of rainfall was observed.

\section{RESULTS}

The speed characteristics of the traffic stream under both rain and no-rain conditions during peak and non-peak periods are presented in table I and table II. In the SkudaiPontian direction, the qualitative performance of the traffic stream can be assessed through table I. At peak period there is progressive reduction in mean speed from no-rain condition to the heavy rain condition. Thus between the three rain conditions there were $2.05 \%, 3.12 \%$ and $6.94 \%$ reductions in speed between the no-rain state and the three rain states of light, medium and heavy respectively. The trend is the same for the median speed as well as the minimum and maximum speeds. In contrast, there were $2.81 \%, 2.28 \%$ and $6.28 \%$ speed reductions during the nonpeak periods between the no-rain conditions and the three rain states of light, medium and heavy. In all conditions of flow during peak period, the $85 \%$ and $95 \%$ of the driver population travelled at speeds below the posted speed limit. This is an indication of vehicle clustering or lack of overtaking opportunities in both weather conditions.

TABLE I

PEAK AND Non-PEAK PERIOD SPEEd CHARACTERISTICS FOR Both RAIN AND No RAIn CONDITIONS IN THE SKUDAI-PONTIAN DiRECTION.

\begin{tabular}{|c|c|c|c|c|}
\hline \multirow{2}{*}{ Speed Characteristics } & \multicolumn{2}{|c|}{ Dry Weather } & \multicolumn{2}{|c|}{ Wet Weather } \\
\hline & \multicolumn{4}{|c|}{ PEAK PERIOD (5.6pm) and $(6 .-7 \mathrm{pm})$} \\
\hline $\operatorname{Mean}(\mathrm{km} \mathrm{hr})$ & $\begin{array}{c}\text { No Rain } \\
54.21\end{array}$ & $\begin{array}{l}\text { Light Rain } \\
53.10\end{array}$ & $\begin{array}{c}\text { Medum Rain } \\
\$ 2.52\end{array}$ & $\begin{array}{c}\text { Heavy Fain } \\
50.45\end{array}$ \\
\hline $\operatorname{Median}(\mathrm{km} / \mathrm{hr})$ & 54.03 & 53.49 & $\$ 2.07$ & 50.23 \\
\hline $\operatorname{Stdev}(\mathrm{km} / \mathrm{hr})$ & 3.00 & 4.19 & 4.25 & 4.83 \\
\hline $\operatorname{Min}(\mathrm{km} / \mathrm{hr})$ & 48.14 & 40.55 & 40.33 & 42.28 \\
\hline $\operatorname{Max}(\mathrm{km} / \mathrm{hr})$ & 63.77 & 63.60 & 60.96 & 57.94 \\
\hline $85 \%$ Speed $(\mathrm{km} / \mathrm{hr})$ & 57.57 & 57.34 & $\$ 6.85$ & 55.52 \\
\hline $\begin{array}{l}95 \% \text { Speed }(\mathrm{km} \mathrm{hr}) \\
\text { Variance }\end{array}$ & $\begin{array}{l}59.19 \\
9.05\end{array}$ & $\begin{array}{l}59.36 \\
17.58\end{array}$ & $\begin{array}{l}39.66 \\
18.07\end{array}$ & $\begin{array}{l}57.94 \\
23.34\end{array}$ \\
\hline \multicolumn{5}{|c|}{ NON-PEAK PERIOD } \\
\hline $\operatorname{Mean}(\mathrm{km} / \mathrm{hr})$ & 58.65 & 57.00 & 57.31 & 54.96 \\
\hline $\operatorname{Median}(\mathrm{km} / \mathrm{hr})$ & 58.5 & 57.45 & $\$ 6.85$ & 56.63 \\
\hline $\mathrm{Stdev}(\mathrm{km} / \mathrm{hr})$ & 2.53 & 4.34 & 4.01 & 4.25 \\
\hline $\operatorname{Min}(\mathrm{km} / \mathrm{hr})$ & 48.19 & 44.05 & 45.51 & 45.70 \\
\hline $\operatorname{Max}(\mathrm{km} / \mathrm{hr})$ & 76.91 & 67.39 & 65.69 & 64.41 \\
\hline $\begin{array}{l}85 \% \text { Speed }(\mathrm{km} / \mathrm{hr}) \\
95 \% \text { Speed }(\mathrm{km} / \mathrm{hr}) \\
\text { Variance }\end{array}$ & $\begin{array}{l}61.01 \\
62.98 \\
8.33\end{array}$ & $\begin{array}{l}60.98 \\
63.75 \\
18.40\end{array}$ & $\begin{array}{l}61.04 \\
63.51 \\
13.98\end{array}$ & $\begin{array}{l}60.21 \\
63.77 \\
24.99\end{array}$ \\
\hline Confidence Interval (95\%) & $62.98=18$ & $63.75=0.47$ & $63.51=0.95$ & $63.77=1.18$ \\
\hline
\end{tabular}

The Pontian-Skudai direction speed characteristics shown in table II also exhibited a similar trend. At peak flow there was decrease in speed between the no-rain condition and the light rain condition as well as the medium rain condition. However, no heavy rain event was recorded during the peak period of $5.00 \mathrm{pm}-7.00 \mathrm{pm}$ in this direction. Thus the decrease in speed between the two rain states (light and medium) and the no-rain state are $2.72 \%$ and $6.77 \%$. For the non-peak period, the reduction in speed progressively decreased by $5.75 \%$ for light rain, $6.42 \%$ for medium rain and $12.33 \%$ for heavy rain. The higher decreases in the speed during non-peak periods may be due to available large headways between vehicles during this period. On the contrary, in peak period headways are much smaller and drivers' manoeuvrability decreases, hence no dramatic speed drops results.

Additional qualitative performance indicator is the Percentile speed profile of the traffic stream during peak and non-peak periods. In the Pontian direction, the 85 percentile speeds during the peak hour were all below the posted speed of $60 \mathrm{~km} / \mathrm{hr}$. and these decreased as the rain intensity 
increased. Interestingly, the 95 percentile speeds were also below the posted speed limit. In the non-peak flows, the norain and the light rain conditions have speeds above the posted limit at both the $85 \%$ and the $95 \%$ percentile speeds. A similar trend was observed for the Skudai direction for both peak and non-peak flows. Thus traffic at peak flow is constrained and deteriorates further with increase in rain intensity. At non-peak periods the effect of rainfall is more dramatic because of the widely available vehicle headways. However, the constriction of flow due to rain does not reduce the speed to below the posted speed limit. In all conditions of flow, the free flow speed is above the posted speed limit and barring any physical incidences, the facility could operate without problems in all rainfall intensity regimes covered in this study.

TABLE II

PEAK AND NON-PEAK PERIOD SPEED CHARACTERISTICS FOR BOTH RAIN AND NO-RAIN CONDITIONS IN THE PONTIAN-SKUDAI DIRECTION.

\begin{tabular}{|c|c|c|c|c|}
\hline \multirow[t]{3}{*}{ Speed Characteristics } & \multicolumn{2}{|c|}{$\begin{array}{l}\text { Dry Weather } \\
\text { PEAK PER!OD (7.8am) }\end{array}$} & \multicolumn{2}{|l|}{ Wet Weather } \\
\hline & No & Light & Medium & Heavy \\
\hline & Rain & Rain & Rain & Rain \\
\hline $\operatorname{Mean}(\mathrm{km} / \mathrm{hr})$ & 56.12 & 54.59 & 52.32 & - \\
\hline $\operatorname{Median}(\mathrm{km} / \mathrm{hr})$ & 53.39 & 52.26 & 53.87 & . \\
\hline $\operatorname{Stdev}(\mathrm{km} / \mathrm{hr})$ & 5.40 & 5.64 & 4.06 & . \\
\hline $\operatorname{Min}(\mathrm{km} / \mathrm{hr})$ & 49.50 & 46.60 & 42.42 & - \\
\hline $\operatorname{Max}(\mathrm{km} / \mathrm{hr})$ & 69.73 & 62.00 & 58.59 & . \\
\hline $35 \%$ Speed $(\mathrm{km} / \mathrm{hr})$ & 63.23 & 59.87 & 56.53 & \\
\hline $95 \%$ Speed $(\mathrm{km} / \mathrm{hr})$ & 69.73 & 61.91 & 57.93 & \\
\hline Vaniance & 29.21 & 31.76 & 16.45 & - \\
\hline $\begin{array}{c}\text { Confidence Interval } \\
(95 \%)\end{array}$ & $69.73=1.64$ & $51.91=0.05$ & $57.93 \pm 1.99$ & \\
\hline & NON-P & AK PERIOD & & \\
\hline $\operatorname{Mean}(\mathrm{km} / \mathrm{hr})$ & 59.67 & 56.24 & 55.84 & 52.31 \\
\hline $\operatorname{Median}(\mathrm{km} / \mathrm{hr})$ & 58.82 & 56.40 & 55.59 & 52.84 \\
\hline $\operatorname{Stdev}(\mathrm{km} / \mathrm{hr})$ & 3.72 & 3.96 & 3.88 & 6.28 \\
\hline $\mathrm{Min}(\mathrm{km} / \mathrm{hr})$ & 49.83 & 69.50 & $\$ 3.43$ & 40.43 \\
\hline $\operatorname{Max}(\mathrm{km} / \mathrm{hr})$ & 76.04 & 43.31 & 70.00 & 67.41 \\
\hline $85 \%$ Speed $(\mathrm{km} / \mathrm{hr})$ & 63.43 & 60.14 & 59.78 & 57.51 \\
\hline $95 \%$ Speed $(\mathrm{km} / \mathrm{hr})$ & 66.31 & 62.89 & 51.61 & 63.65 \\
\hline Vaniance & 13.82 & 15.67 & 15.03 & 39.41 \\
\hline $\begin{array}{c}\text { Confidence Interval } \\
(95 \%)\end{array}$ & $66.31=0.26$ & $52.89=0.37$ & $61.61=0.69$ & $63.65=1.50$ \\
\hline
\end{tabular}

The quantitative assessment of the facility can be made by computing the flows and densities during peak and non-peak periods and for the conditions of rain and no rain. This is made possible by obtaining the model equations for the speed-density and flow-density fundamental relationships. The speed-density relationship first derived by [14] is combined with the fundamental equation of traffic to obtain the flow-density or speed-flow model equations as the case may be. The speed-density and speed-flow models are as stated in equations 1 and 2 .

$$
\begin{gathered}
q=\mu_{f}-\frac{\mu_{f}}{k_{j}} k \\
q=\mu_{f} k-\frac{\mu_{f}}{k_{j}} k^{2}
\end{gathered}
$$

These equations are used in conjunction with the flowdensity models to obtain the traffic states on the facility.

The empirical models for the no-rain condition and the rain intensity conditions for light, medium and heavy are shown in fig 1 to 4 . Each figure has three plots depicting a comparison between the no-rain conditions and each of the three rain states. Because the peak period changes with the direction having the predominant flow, the data was analysed separately for each direction.

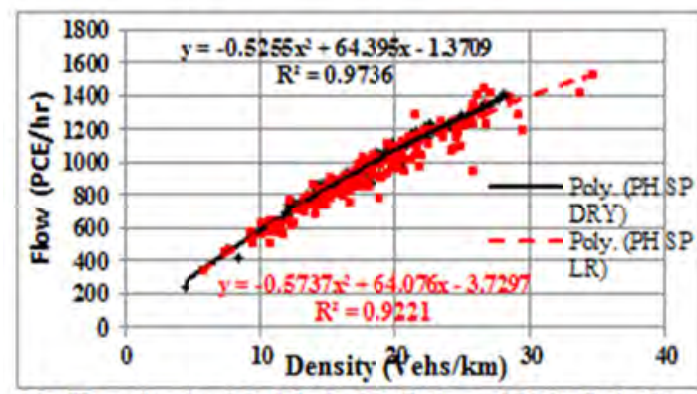

(a) Flow-density Models for No-Rain and Light Rain Condition

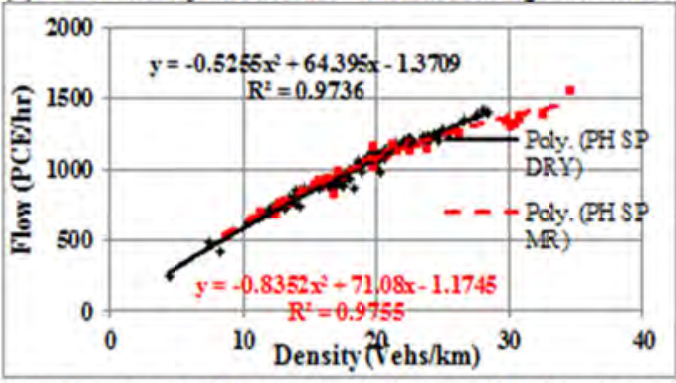

(b) Fow-density Models for No-Rain andMedium Rain Condition

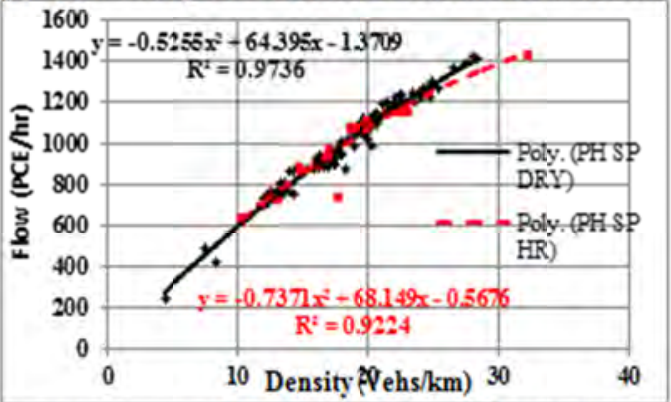

(c) Flow-density Models for No-Rain and Heavy Rain Condition

Fig 1: Flow-Density Empirical Models between No-Rain and Rain Conditions during Peak Periods in the Skudai-Pontian Direction. (a) NoRain and Light Rain; (b) No-Rain and Medium Rain and (c) No-Rain and Heavy Rain. For clarity, the dry condition model is in black colour while the rain condition is in red. 


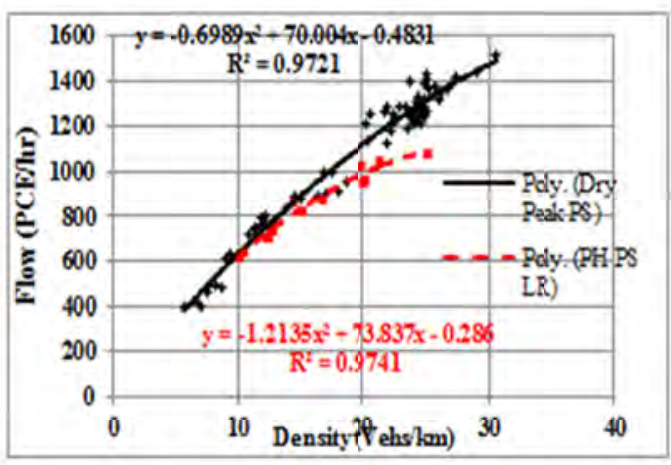

(a) Flow-Density Models for No-Rain and Light Rain Condition

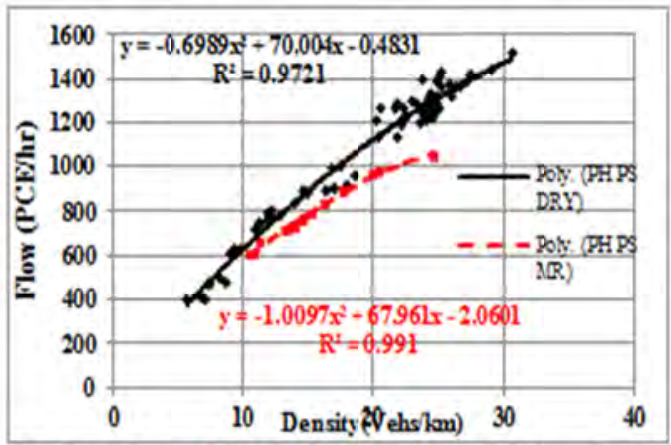

(b) Fow-density Models for No-Rain andMedium Rain Condition

Fig 2: Flow-Density Empirical Models between No-Rain and Rain Conditions during Peak Periods in the Pontian-Skudai Direction. (a) NoRain and Light Rain; (b) No-Rain and Medium Rain and (c) No-Rain and Heavy Rain. For clarity, the dry condition model is in black colour while the rain condition is in red.

The empirical evidence for the existence of traffic flow contraction in adverse weather is clearly discernible from the plots. The summary of the traffic flow states derived from the model equations are shown in tables 3 for peak period flows and table 4 for non-peak period flows. The capacity for the section in both directions decreases as the rain intensity increases. In the Pontian direction, the capacities dropped by $9.44 \%$ between no-rain and light rain condition, $23.34 \%$ between no-rain and medium rain condition , and $20.09 \%$ between no-rain and heavy rain condition. The critical speeds are at about half of the posted speed limit. In the Skudai direction, the capacity reductions are $35.90 \%$ for light rain and $34.82 \%$ for medium rain. No heavy rain event was observed in this direction for this study. The Pontian direction carries the higher flows during the morning peak while the Skudai direction carries the higher flows in the evening peak. Moreover, the evening peak is spanned over a longer period than the morning peak and it is not clear why this direction has a higher capacity loss.

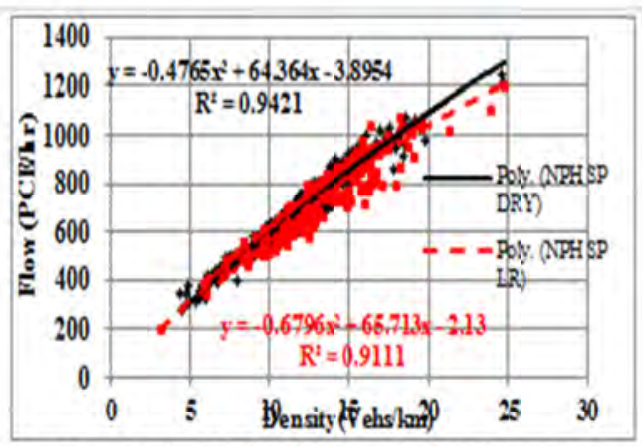

(a) Fow-density Models for No-Rain and Light Rain Condition

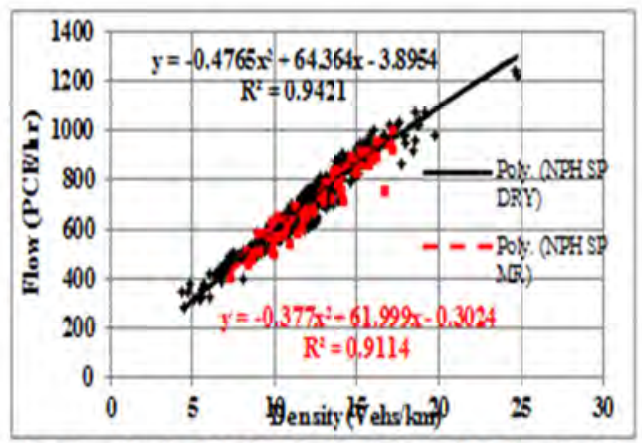

(b) Fow-density Models for No-Rain andMedium Rain Condition

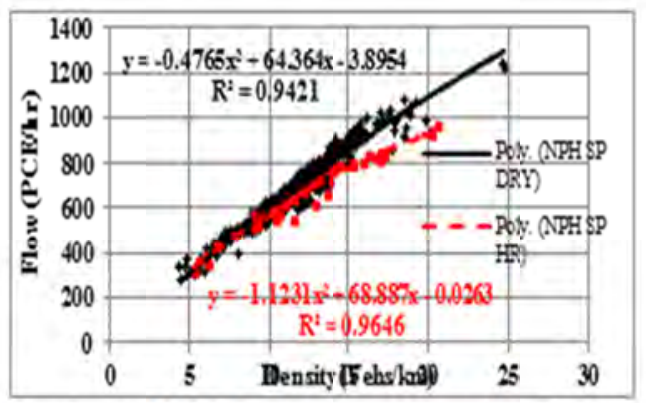

6. Flow-density Models for No-Rain and heavy Rain Condition

Fig 3: Flow-Density Empirical Models between No-Rain and Rain Conditions during Non-Peak Periods in the Skudai-Pontian Direction. (a) No-Rain and Light Rain; (b) No-Rain and Medium Rain and (c) No-Rain and Heavy Rain. For clarity, the dry condition model is in black colour while the rain condition is in red.

The capacity losses during the non-peak periods show a progressive decrease of capacity as the rainfall intensity increased. The Pontian direction has $26.91 \%$ reduction in capacity for light rain, 41.25\% reduction for medium rain and $51.34 \%$ for heavy rain. The Skudai direction, on the other hand, has $4.23 \%$ capiacity reduction in light rain condition, $21.94 \%$ in medium rain condition and $41.47 \%$ in heavy rain condition. Both directions carry equivalent amount of traffic during non-peak periods but the Skudai direction has a higher capacity drop that the Pontian direction. Compared to the peak period capacity reductions, the non-peak values are higher due probably to the higher vehicles headways available in the traffic stream and hence can undergo larger contraction of the flow than the peak period. 


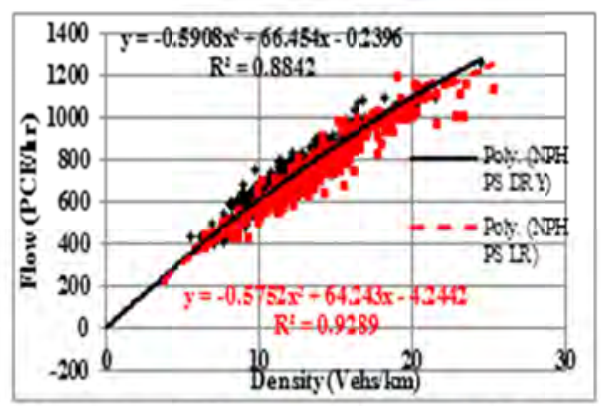

(a) Fow-density Models for No-Rain and Light Rain Condition

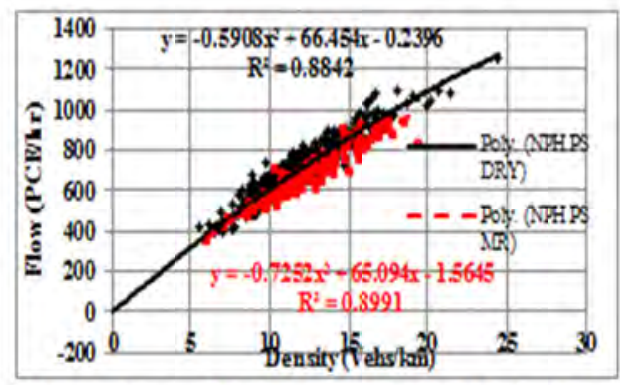

(b) How-density Models for No-Rain andMedium Rain Condition

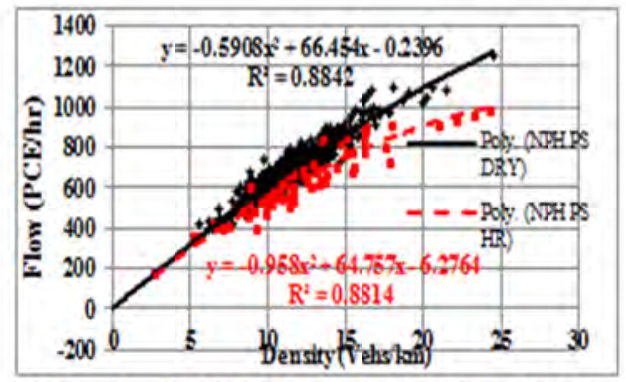

8. Fow-density Models for No-Rain andheavy Rain Condition

Fig 4: Flow-Density Empirical Models between No-Rain and Rain Conditions during Non-Peak Periods in the Pontian-Skudai Direction. (a) No-Rain and Light Rain; (b) No-Rain and Medium Rain and (c) No-Rain and Heavy Rain. For clarity, the dry condition model is in black colour while the rain condition is in red.

TABLE III

TRAFFic STATES For PEAK PERIODS In BOth DiReCtions.

\begin{tabular}{|c|c|c|c|c|}
\hline Traffic State & Dry Weather & \multicolumn{3}{|c|}{$\begin{array}{c}\text { Wet Weather } \\
\text { SKLDAI-PONTIAN DIRECTION }\end{array}$} \\
\hline Mean Speed $(\mathrm{km} / \mathrm{hr})$ & $\begin{array}{l}\text { No Rain } \\
54.21\end{array}$ & $\begin{array}{l}\text { Light Rain } \\
53.10\end{array}$ & $\begin{array}{l}\text { Medium Rain } \\
5252\end{array}$ & $\begin{array}{l}\text { Heavy Ram } \\
50.44\end{array}$ \\
\hline Speed at Capacity(km/hr) & 32.18 & 3197 & 3551 & 34.06 \\
\hline Current Density(vehs/kn) & 18.07 & 18.02 & 19.47 & 18.03 \\
\hline Critical Density(vehs/kn) & 61.27 & 55.85 & 42.55 & 46.23 \\
\hline Current Volume(pce/hril) & 972 & 948 & 1015 & 909 \\
\hline \multirow[t]{3}{*}{ Capacity (pce/hr/) } & 1971 & 1785 & 1511 & 1575 \\
\hline & \multicolumn{4}{|c|}{ PONTLAN-SKLDAI DIRECTION } \\
\hline & No Rain & Light Rain & Medium Rain & Heavy Rau \\
\hline Nean Speed (km/hr) & 56.12 & 54.59 & 5232 & : \\
\hline Speed at Capacito(km/hr.) & 34.99 & 36.91 & 3392 & . \\
\hline Current Density(vehs/kn) & 19.78 & 15.84 & 1535 & . \\
\hline Critical Density(vehs/km) & 50.08 & 30.42 & 33.65 & . \\
\hline Current Volume(pce/hri) & 1081 & 842 & 789 & . \\
\hline Capacitv (pce/hr/) & 1752 & 1123 & 1142 & . \\
\hline
\end{tabular}

TABLE IV

TRAFFic STATES FOR NON-PEAK PERIODS IN BOTH DiRECTIONS

\begin{tabular}{|c|c|c|c|c|}
\hline Traffic State & Dry Weather & \multicolumn{3}{|c|}{$\begin{array}{c}\text { Wet Weather } \\
\text { SKLDAI-PONTLAN DIRECTION }\end{array}$} \\
\hline Mean Speed $(\mathrm{km} / \mathrm{kr})$ & $\begin{array}{l}\text { No Rain } \\
58.65\end{array}$ & $\begin{array}{l}\text { Light Rain } \\
57.00\end{array}$ & $\begin{array}{l}\text { Medium Rain } \\
57.31\end{array}$ & $\begin{array}{l}\text { Heavy Rain } \\
54.96\end{array}$ \\
\hline Speed at Capacity(km/hr) & 32.12 & 32.81 & 30.99 & 34.44 \\
\hline Current Density(vehs/km) & 11.27 & 12.58 & 12.36 & 12.39 \\
\hline Critical Densityy(vehs km) & 67.54 & 48.35 & 41.11 & 30.67 \\
\hline Current Volume(pce/hrI) & 658 & 710 & 106 & 665 \\
\hline \multirow[t]{3}{*}{ Capacity (pce/hr/) } & 2170 & 1586 & 1274 & 1056 \\
\hline & \multicolumn{4}{|c|}{ PONTIAY-SKLDAI DIRECTION } \\
\hline & No Rain & Light Rain & Medim Rain & Heavy Ruir \\
\hline Mean Speed (km/rr) & 59.67 & 56.26 & 55.84 & 5231 \\
\hline Speed at Capacio(kn/hr.) & 33.23 & 32.04 & 32.51 & 3238 \\
\hline Current Density (vehskm) & 11.44 & 13.35 & 12.59 & 12.52 \\
\hline Critical Densityy(rehskm) & 56.24 & 55.84 & 4.88 & 33.80 \\
\hline Current Volume(pce/hrI) & 681 & 744 & 698 & 639 \\
\hline Capacity (pce/hr/) & 1869 & 1790 & 1459 & 1094 \\
\hline
\end{tabular}

\section{CONCLUSIONS}

The impact of rainfall on traffic flow during peak and non-peak periods have been examined in this study. Speed reductions and flow contractions are common features of traffic flows under adverse weather conditions. These can cause undesirable effects such as delays and congestion among others. The conclusions in this study are:

Rainfall affects traffic during peak periods and non-peak periods. The reductions in speed are higher in non-peak periods than during peak flows because of widely available gaps in the traffic stream. During peak periods the flows are highly constrained and the effect of rain is to marginally reduce the speed.

Flow rates are also affected during rainfalls and could result in capacity reductions. Capacity reductions during peak periods would have a greater impact on the traffic flows than during non-peak periods. Such reductions could lead to queue build up, slow moving traffic and long delays. Driver apprehension in these situations could also lead to unsafe driving behaviour.

Capacity reductions up to $30 \%$ during peak periods would require resources to be employed to assist drivers.

\section{ACKNOWLEDGMENT}

The authors wish to thank the Department of Drainage and Irrigation of Malaysia (JPS) for supplying the rainfall data.

\section{REFERENCES}

[1] Alhassan, H.M. and J. Ben-Edigbe, Effect of Rainfall on Microscopic Traffic Flow Parameters. Proceedings, Malaysian Universities Transportation Research Forum and Conference,Putrajaya,Malaysia, 2010b: p. 117-126.

[2] Alhassan, H.M. and J. Ben-Edligbe, Highway Capacity Loss Induced by Rainfall. Proceedings: Intternational Conference on Advanced Science,Engineering and Information Technology, 2011(Hotel Equatorial Bangi-Putrajaya, Mialaysia): p. 231-239.

[3] Aggarwal, M., T.H. Maze, and R. Souleyrette, The Weather and Its Impact on Urban Freeway Traffic Operations. Proceedings of the 85th Annual Meeting of the Transportation Research Board. Transportation Research Board of the National Academies, Washington, D.C., 2006.

[4] Billot, R., et al., How Does Rain Affect Traffic Indicators?: Empirical Study on a French Interurban Mortorway. Proceedings of lake side Conference, Klagenfurt, Austria, 2008.

[5] Tanner, J.C., Effect of Weather on traffic Flow. Nature, 1952. 4290: p. 107.

[6] Changnon, S.A., Effects of Summer Precipitation on Urban Transportation. . Climatic Change 1996. 32: p. 481-494. 
[7] Hogema, J.H., Effects of Rain on Daily Traffic Volume and on Driving Behavior. . TNO report TM-96-B019, TNO Human Factors Research Institute, Soesterberg, Te Netherlands., 1996

[8] Smith, B.L., et al., An Investigation into the Impact of Rainfall on Freeway Traffic Flow. . In Proceedings of the 83rdannual meeting of the Transportation Research Board. CDROM. Transportation Research Board of the National Academies, Washington, D.C., 2004.

[9] Codling, P.J., Weather and Road Accicdents.In: ed.Taylor J.A Climatic Resources and economic activity. A symposium, 1974: p. 205-222.
[10] Chung, E., O. Ohtani, and M. Kuwahara, Effect of Rainfall on Travel Time and Travel Demand. . 5th ITS European Congress, Hannover, Germany., 2005a

[11] Chung, E., et al., Does Weather Affect Highway Capacity. 2006.

[12] Alhassan, H.M. and J. Ben-Edigbe, Effect of Rainfall Intensity Variability on Highway Capacity. European Journal of Scientific Research, 2011b. 49(1): p. 123-129.

[13] Alhassan, H.M. and J. Ben-Edigbe, Highway Capacity Prediction in Adverse Weather. Journal of Applied Sciences, 2011c. 11(12): p. 2193-2199.

[14] Greenshields, B.D., A Study of Traffic Capacity. Highway Research Board Proceedings, 1935. 14: p. 448-477. 